\title{
Platelet-rich plasma in diabetic dry eye disease
}

\author{
Plasma rico em plaquetas no olho seco diabético
}

Marina Viegas Moura Rezende Ribeiro', Fabiano Timbó Barbosa'1, Luiz Eduardo Feliciano Ribeiro², Celina Maria Costa Lacet $^{3}$ João Marcelo de Almeida Gusmão Lyra ${ }^{3}$, Verônica de Lima Guedes ${ }^{4}$, Patrícia Costa Alves Pinto ${ }^{3}$,Eurica Adélia Nogueira Ribeiro'

\begin{abstract}
Objective: To evaluate the effectiveness of autologous Plasma- rich platelet (PRP) in symptomatic dry eye of diabetic patients. Design: $A$ prospective single group interventional study. Participants: Twelve diabetic patients with refractory dry eye disease. Methods: Patients were treated with autologous PRP eye drops four times a day for a month. Dry eye symptoms and its frequency, according to DEWS studies, tear film breakup time, improvement of visual acuity lines, and Schirmer test. Results: All the patients had some symptomatic improvement regarding dryness, itching, burning and redness ( $p=0.002)$. Five patients, 41.66\% (5/12) had improvement of 1 or more lines of visual acuity in both eyes, $50 \%$ and $58.33 \%$ had no alteration in right and left eye, respectively ( $p=0.14)$. Considering Schirmer test, $66.66 \%(8 / 12)$ had improvement in the test value, $25 \%(3 / 12)$ had no alteration in this test value and $8.33 \%(1 / 12)$ had a reduced value in the test after treatment. $(p=0.04)$. Considering the value of BUT test $58.33 \%(7 / 12)$ had improvement in the test value and $41.66 \%(5 /$ 12) had no alteration in this test value ( $p=0.018)$. Conclusions: $P R P$ is safe and an interesting alternative therapy in symptomatic diabetic dry eye. More clinical trials are required to create specific protocols to this treatment.
\end{abstract}

Keywords: Dry eye syndromes; Diabetes/complications; Platelet-rich plasma

\section{RESUMO}

Objetivo: Avaliar a eficácia do colírio de concentrado de plaquetas (CCP) autólogo no olho seco sintomático de pacientes diabéticos. Projeto: Um estudo de intervenção único grupo prospectivo. Participantes: Doze pacientes diabéticos com doença do olho seco refratário. Métodos: Os pacientes foram tratados com colírio de PRP autólogo quatro vezes por dia durante um mês. Sintomas de olho seco e sua frequência, seguindo os critérios de DEWS, tempo de ruptura do filme lacrimal, a melhoria das linhas de acuidade visual e teste de Schirmer. Resultados: Todos os pacientes tiveram alguma melhora dos sintomas de ressecamento, coceira, ardor e vermelhidão ( $\mathrm{p}=0,002)$. Destes, $41,66 \%(5 / 12)$ tiveram melhora de uma ou mais linhas de acuidade visual em ambos os olhos; $50 \%$ e $58,33 \%$ não tinham alteração no olho direito e esquerdo, respectivamente $(\mathrm{p}=0,14)$. Considerando o teste de Schirmer, $66,66 \%$ (8/12) tiveram melhora no valor do teste, $25 \%$ (3/12) não apresentaram alteração neste valor de teste e de 8,33\% (1/12) tiveram um valor reduzido no teste após tratamento. $(\mathrm{p}=0,04)$. Considerando o valor de teste BUT 58,33\% $(7 / 12)$ apresentaram melhora no valor de teste e $41,66 \%(12 / 05)$ não apresentaram alteração neste valor de teste $(\mathrm{p}=0,018)$. Conclusões: O CCP é seguro e uma terapia alternativa interessante no olho seco diabético sintomático. Mais ensaios clínicos são necessários para criar protocolos específicos para este tratamento.

Descritores: Síndromes do olho seco; Diabetes/complicações; Plasma rico em plaquetas

\footnotetext{
${ }^{1}$ Universidade Federal de Alagoas, Maceió, AL, Brazil.

2 Instituto de Olhos de Maceió- Alagoas, Brazil

${ }^{3}$ Universidade de Ciências da Saúde de Alagoas, Maceió, AL, Brazil.

${ }^{4}$ Hemocentro de Alagoas, Maceió, AL, Brazil.

The authors declare no conflicts of interests.

Received for publication 03/02/2016 - Accepted for publication 07/03/2016
} 


\section{INTRODUCTION}

I $\mathrm{n}$ addition to retinopathy, that can lead to blindness, diabetic patient also have more tendency to develop dry eye. The prevalence of dry eye in this population ranges between $14,4 \%$ to $54,3 \%{ }^{1}$ Dry eye disease is a major tear deficiency disorder which may lead to discomfort, visual disturbances and tear film instability, with potential damage to the ocular surface ${ }^{2}$ and can evaluate with complications like vision deficit, scarring and cornea perforation. Most diabetic patients have classic symptoms of dry eye and they usually also have alterations in Schirmmer test. ${ }^{3}$ Autonomic dysfunction and tear dysfunction are the main mechanisms involved in development of dry eye in these patients. ${ }^{4}$

Treatment of dry eye may not be satisfactory because of the multifactorial etiology of dry eye, the lack of correlation between symptoms and objective clinical tests, and unavailability of a commercial tear substitute that is ideal in terms of its properties. Severe dry eye cases are usually unresponsive to conventional artificial tears. ${ }^{5}$

Platelet-rich plasma (PRP) has been used for over a decade in different clinical areas like orthopedics ${ }^{6}$, and maxillofacial surgery ${ }^{7}$, but only recently has PRP been introduced in Ophthalmology practice. ${ }^{8,9,10}$

PRP obtained from total unclogged blood is very rich in platelets and growth factors, including platelet-derived angiogenesis factor, platelet-derived growth factor, platelet derived epidermal growth factor and platelet factor IV, and others that emulate physicochemical properties of natural tears. ${ }^{11}$ PRP had shown improvement in ocular surface regeneration, in cases of micropunctate keratitis, decrease inflammation, accelerate and stimulate wound healing processes and may also have a lubricant effect. PRP is also more efficient than total plasma serum in these functions ${ }^{10}$. There are few studies using PRP in dry eye, ${ }^{5,12}$ and none, to the best of our knowledge, in diabetic dry eye patients specifically.

Patients with diabetes exhibit, in addition to vascular alterations, modifications in blood, as shown in recent studies. A prothrombotic milieu consisting of hyper reactive platelets produce a tight and rigid clot structure which is due to upregulation of coagulation factors and prolongation of clot lysis ${ }^{13}$. Considering this fact, this study represents a first approach to evaluate the use of PRP as an alternative treatment of symptomatic (moderate to severe) diabetic dry eye, unresponsive to conventional treatment.

\section{Methods}

This was a prospective, nonrandomized, observational consecutive study. We recruited 221 diabetic patient at the Hospital Universitário Dr.Alberto Antunes (Maceió, Alagoas-Brazil.) from December 2014 to July 2015, following recommendations of the Declaration of Helsinki, approval by the National Ethical Committee and informed consent of the patients. They were evaluated for use of systemic medication and eyedrops, other clinical or ocular diseases and previous ocular surgeries. Dry eye severity was established by the Dry Eye Workshop (DEWS) severity scheme, and patient examination included best spectacle corrected visual acuity (BSCVA) measured by Snellen charts and expressed in number of lines improvement and also in $\log \mathrm{MAR}$ means before and after treatment, cornea and conjunctiva staining, lacrimal meniscus height, signs of meibomius glands disfunction, keratitis, other biomicroscopic alterations, tonometry, fundoscopy, Schirmer test and Break up time test (BUT).

We evaluated the severity of the perceived symptoms, analyzed by their frequency, using the classical symptoms of dry eye: dryness, itching or foreign body sensation, burning, redness, blurred vision and mucus or crusting. Each symptom was graduated from 1 to 4 (never or mild, sometimes, frequent and constant, respectively).

BUT test was performed with application of fluorescein to the cornea and matching the time between the last blink and the appearance of the first dark spot. It is considered normal if it appears after or at 10 seconds. It was graduated from 1 to 4 (variable or more than 10 seconds, less than 10 seconds, less than 5 seconds and immediate respectively).

Schirmer test was performed without anesthesic eye drops (Teste de Schirmer Ophthalmos S.A.) using a filter paper strip inside the lower eyelid of each eye. Both eyes were tested at the same time. The patient were asked to close their eyes gently for 5 minutes. After 5 minutes, the physician removes the paper and measures how moist it is. The values were graduated from 1 to 4 $(11 \mathrm{~mm}$ or more, $10 \mathrm{~mm}$ or less, less than $5 \mathrm{~mm}$, and less than $2 \mathrm{~mm}$ respectively).

Inclusion criteria for PRP treatment was presence of diabetes according to American Diabetes Association criteria, unresponsiveness or a weak response to conventional treatment, having at least a frequent or constant symptom and either a Schirmer test at less than $15 \mathrm{~mm}$ or a BUT less than 10 seconds. Exclusion criteria were patients that had keratopathies, use of glaucoma eyedrops and previous rheumatic disease diagnosis. We also excluded patient that had contraindicated conditions to autologous donation (congest heart failure, severe aortic stenosis, heart attack or stroke in the last 6 months, angina, cyanotic disease, infection or antibiotics use.

Previous treatment was stopped 48 hours before starting PRP drops, and the patients were reexamined weekly until 1 month after initial treatment with PRP. Main outcomes measures were evaluation of symptoms, improvement in best corrected visual acuity, BUT and Schirmmer test .

\section{PRP Preparation and Treatment Regime}

Patients were referred to HEMOAL (Alagoas Blood Center) and underwent venipuncture to obtain $350 \mathrm{ml}$ of whole blood in a triple bag with previously prepared SAG mannitol as an anticoagulant, and CPD (sodium citrate, phosphate and dextrose) as a preservative. The blood was processed in a refrigerated centrifuge (SORVALL-RC3BP +) where in the first centrifugation, plasma was separated from erythrocytes in a frequency of $2000 \mathrm{rpm}$ for 5 minutes; and in the second centrifugation to separate the plasma from the platelets, the frequency was $3800 \mathrm{rpm}$ for 10 minutes. The final product, which was the random platelet concentrate, was prepared in sterile room in laminar flow and stored within the sterile $5 \mathrm{ml}$ eye drop bottles with calcium gluconate as the carrier. Eye drops bottles were routed to CPML Microbiology Service (Pathology Laboratory Medical Center at University of Health Sciences of Alagoas), and culture to fungus and bacteria were done. The bottle in use was recommended to be kept at $+4^{\circ} \mathrm{C}$ and the rest at $-20^{\circ} \mathrm{C}$ at HEMOAL. Patients were advised to discard the bottle in use every 5 days and get a new bottle, stored at $-20^{\circ} \mathrm{C}$, thawed for new use ( 6 bottles per patient). 
The solution was to be applied 4 times per day. Patients were evaluated every week until 1 month. The one month examination data was analyzed.

\section{Statistical methods}

Means and SDs of the "age " variable and the millimeters values of Schirmer test were calculated, and median and interquartile range of all other variables were calculated using Biostat 5.3 software. Scoring on the degree of pretreatment and post treatment symptoms and signs were compared using the paired 2-tailed Wilcoxon test to determinate the degree of statistical significance, and values of $\mathrm{p}<0.05$ were considered to be statistically significant.

\section{ResUlts}

A total of 58 out of the 221 diabetic patient accessed fulfilled the criteria for PRP treatment, having moderate to severe dry eye (one or more classical symptom graduated as 3 or 4 and a BUT test at less than 10 seconds and/or Schirmer test less than $15 \mathrm{~mm}$ ). Of those 58, 25 were excluded for various reasons and 9 were satisfied using commercial lubricants despite their symptoms and clinical signs. The 25 remaining patients were then screened for conditions that would contraindicate or impede autologous donation, and 12 were excluded. Finally, one patient lost follow up. (Figure 1)

Therefore, 12 patients were submitted to the PRP treatment and evaluated in this study (11 women and one man). Mean age of the patients was $59.5+-11.58(\mathrm{SD})$.

Global results for symptoms are compiled in tables 1 and 2 and clinical signs in table 3 .

\section{Symptoms}

Considering dryness, patients had a median grade of 3(3$3)$ before PRP, and 1(1-2) after one month $(\mathrm{p}=0.002)$. Although $100 \%(12 / 12)$ referred improvement, $66.66 \%(8 / 12)$ had total absence of this symptom and $33,33 \%$ (4/12) had some improvement.

As for itching and foreign body sensation, patients had a median grade of 3(3-3) before PRP, and $1.5(1-2)$ after $(\mathrm{p}=0.002)$. Although 100\% (12/12) had improvement, 50\% (6/12) had total absence of this symptom and 50\% (6/12) had some improvement.

Burning sensation in patients had a median grade of 3 (33 ) before PRP, and 1(1-1) after ( $\mathrm{p}=0.002) ; 100 \%(12 / 12)$ had total absence of this symptom.
Complaints of redness had a median grade of 3(2-3) before PRP, and 1(1-1) after ( $p=0.005)$. Although 100\% (12/12) had improvement, $91,66 \%(11 / 12)$ had total absence of this symptom and $8.33 \%(1 / 12)$ had some improvement.

Regarding crusting and mucus, patients had a median grade of 1(1-1) before PRP, and 1(1-1) after ( $p=0.17)$. Only $16.67 \%$ $(2 / 12)$ had these symptoms before PRP and both reported improvement.

Considering blurred vision, patients had a median grade of 2(1.75-3) before PRP, and 2(1-2) after one month ( $p=0.018)$; $58.33 \%(7 / 12)$ had improvement in this symptom.

\section{Visual acuity}

Number of lines improvement in the right eye: $41.66 \%(5 /$ 12) had improvement of 1 or more lines, $8.33 \%(1 / 12)$ had reduction of at least one line and $50 \%(6 / 12)$ had no alteration in right eye BSCVA. Means $\log$ MAR before the treatment was $\log$ MAR $0.39 \pm 0.32$, and after treatment was $\log$ MAR $0.31 \pm 0.35$ $(\mathrm{p}=0.02)$.

Number of lines improvement in the left eye: $41.66 \%(5 /$ 12) had improvement of 1 or more lines and $58.33 \%(7 / 12)$ had no alteration in left eye BSCVA.

\section{Schirmer test}

We used the average between values of both eyes. Regarding the gradation value of Schirmer test, patients had a median grade of 3(2-3) before PRP, and 2(1-3) after ( $\mathrm{p}=0.11$ ); $41.66 \%(5 / 12)$ had improvement, 50\% (6/12) had no alteration and $8.33 \%(1 / 12)$ had a reduced value in the test after treatment. (Table 4).

Considering the Schirmer value in millimeters for both eyes, we had a median value of 5 (4-9.25) before PRP, and 8 (512.25), after treatment. The mean before was $6.75 \mathrm{~mm} \pm 3.66$, and $8.96 \mathrm{~mm} \pm 4.56$ after treatment. $(\mathrm{p}=0.04)$. In this way, $66.67 \%(8 /$ 12) had improvement in this test, $25 \%(3 / 12)$ had no alteration and 1 patient $(8.33 \%)$ had a worse value after PRP.

BUT test

The value of BUT test in patients had a mean grade of 2.5(2-3) before PRP, and 2(1.75-3) after ( $\mathrm{p}=0.018) .58,33 \%(7 / 12)$ had improvement and $41.66 \%(5 / 12)$ had no alteration in this test value.

We found no cases of poor tolerance or undesirable effects that could be attributed to the use of PRP (Table 5).

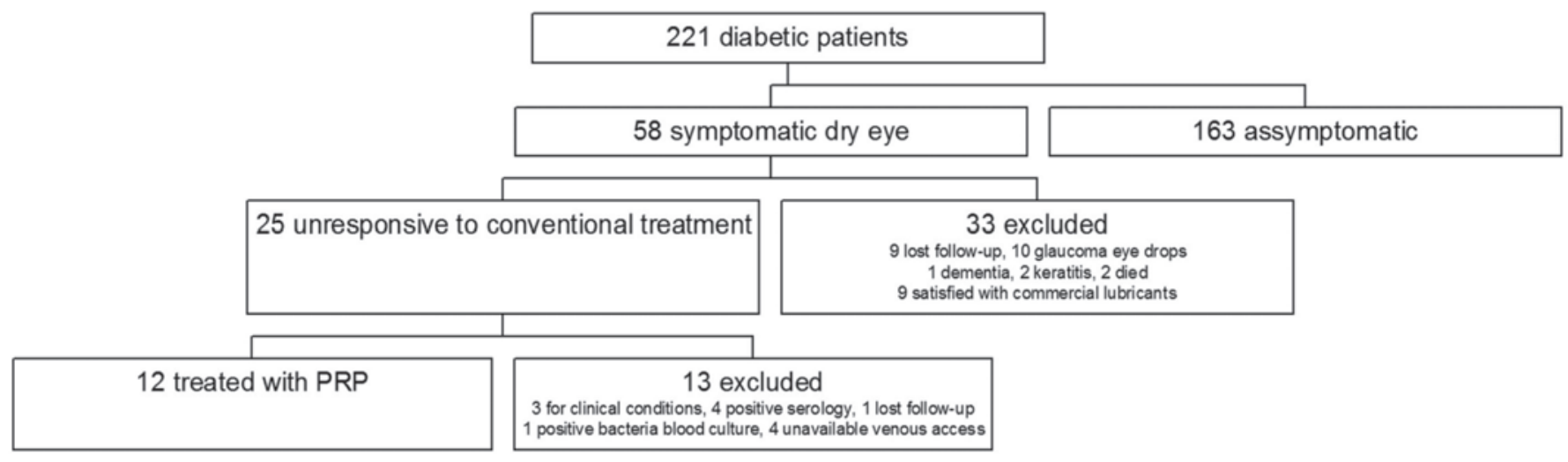

Figure 1: Results flowchart 
Table 1

Symptoms before treatment (Grade)

\begin{tabular}{|c|c|c|c|c|c|c|c|c|}
\hline $\begin{array}{l}\text { Patient } \\
\text { number }\end{array}$ & Sex & Age & Dryness & $\begin{array}{c}\text { Foreign body } \\
\text { sensation / itching }\end{array}$ & Burning & Redness & $\begin{array}{l}\text { Eye mucus } \\
\text { and crusting }\end{array}$ & $\begin{array}{c}\text { Blurred } \\
\text { vision }\end{array}$ \\
\hline 1 & $\mathrm{~F}$ & 68 & 3 & 3 & 3 & 1 & 1 & 1 \\
\hline 3 & $\mathrm{~F}$ & 59 & 3 & 3 & 3 & 3 & 1 & 3 \\
\hline 4 & $\mathrm{~F}$ & 47 & 3 & 3 & 3 & 3 & 1 & 2 \\
\hline 5 & $\mathrm{~F}$ & 69 & 3 & 3 & 3 & 3 & 3 & 3 \\
\hline 8 & $\mathrm{~F}$ & 66 & 3 & 3 & 3 & 2 & 1 & 2 \\
\hline 9 & $\mathrm{M}$ & 40 & 3 & 3 & 3 & 2 & 1 & 1 \\
\hline 10 & $\mathrm{~F}$ & 61 & 3 & 3 & 3 & 3 & 1 & 2 \\
\hline 11 & $\mathrm{~F}$ & 58 & 3 & 3 & 3 & 2 & 1 & 1 \\
\hline 12 & $\mathrm{~F}$ & 52 & 3 & 3 & 3 & 1 & 1 & 2 \\
\hline
\end{tabular}

Blurred vision: 1: none or episodic, 2: annoying and or activity limiting episodic, 3 : annoying and or chronic activity limiting

Table 2

Symptoms after treatment (Grade)

\begin{tabular}{lllcccccc}
\hline $\begin{array}{l}\text { Patient } \\
\text { number }\end{array}$ & Sex & Age & Dryness & $\begin{array}{c}\text { Foreign body } \\
\text { sensation / itching }\end{array}$ & Burning & Redness & $\begin{array}{c}\text { Eye mucus } \\
\text { and crusting }\end{array}$ & $\begin{array}{c}\text { Blurred } \\
\text { vision }\end{array}$ \\
\hline $\mathbf{1}$ & $\mathrm{F}$ & 68 & 2 & 2 & 1 & 1 & 1 & 1 \\
$\mathbf{2}$ & $\mathrm{F}$ & 59 & 1 & 1 & 1 & 1 & 1 & 2 \\
$\mathbf{3}$ & $\mathrm{F}$ & 59 & 1 & 1 & 1 & 1 & 1 & 2 \\
$\mathbf{4}$ & $\mathrm{F}$ & 47 & 1 & 2 & 1 & 1 & 1 & 2 \\
$\mathbf{5}$ & $\mathrm{F}$ & 69 & 1 & 1 & 1 & 1 & 1 & 2 \\
$\mathbf{6}$ & $\mathrm{F}$ & 84 & 1 & 2 & 1 & 1 & 1 & 3 \\
$\mathbf{7}$ & $\mathrm{F}$ & 51 & 2 & 2 & 1 & 2 & 1 & 2 \\
$\mathbf{8}$ & $\mathrm{F}$ & 66 & 1 & 1 & 1 & 1 & 1 & 1 \\
$\mathbf{9}$ & $\mathrm{M}$ & 40 & 1 & 1 & 1 & 1 & 1 & 1 \\
$\mathbf{1 0}$ & $\mathrm{F}$ & 61 & 2 & 2 & 1 & 1 & 1 & 2 \\
$\mathbf{1 1}$ & $\mathrm{F}$ & 58 & 1 & 1 & 1 & 1 & 1 & 1 \\
$\mathbf{1 2}$ & $\mathrm{F}$ & 52 & 2 & 2 & 1 & 1 & 1 & 1 \\
$\mathbf{p}$-value & & & $\mathbf{0 , 0 0 2}$ & $\mathbf{0 , 0 0 2}$ & $\mathbf{0 , 0 0 2}$ & $\mathbf{0 , 0 0 5}$ & $\mathbf{0 , 1 7}$ & $\mathbf{0 , 0 0 1}$ \\
\hline
\end{tabular}

Discomfort symptoms: 1: Mild and or episodic, with stress, 2: moderate episodic or chronic, 3: severe or constant, 4: severe or disabling Blurred vision: 1: none or episodic, 2: annoying and or activity limiting episodic, 3: annoying and or chronic activity limiting

Table 3

Improvement of clinical signs

\begin{tabular}{lllcccc}
\hline $\begin{array}{l}\text { Patient } \\
\text { Number }\end{array}$ & Sex & Age & $\begin{array}{c}\text { VA improvement (number of lines) } \\
\text { Right eye }\end{array}$ & $\begin{array}{c}\text { Deft eye } \\
\text { Schirmer Improvement }\end{array}$ & BUT Improvement \\
\hline $\mathbf{1}$ & & & & & No & No \\
$\mathbf{2}$ & F & 68 & 2 & 0 & Yes & No \\
$\mathbf{3}$ & F & 59 & 0 & 0 & No & Yes \\
$\mathbf{4}$ & F & 49 & 0 & 0 & Yes & Yes \\
$\mathbf{5}$ & F & 69 & 1 & 2 & Yes & Yes \\
$\mathbf{6}$ & F & 84 & 3 & 3 & No & Yes \\
$\mathbf{7}$ & F & 51 & 0 & 0 & Yes & Yes \\
$\mathbf{8}$ & F & 66 & -3 & 1 & No & Yos \\
$\mathbf{9}$ & M & 40 & 0 & 0 & Yes & Yes \\
$\mathbf{1 0}$ & F & 61 & 0 & 0 & No & No \\
$\mathbf{1 1}$ & F & 58 & 0 & 0 & & \\
$\mathbf{1 2}$ & F & 52 & 3 & 2 & & \\
\hline
\end{tabular}

VA: visual acuity 
Table 4

Schirmer I test before and after PRP- grade

\begin{tabular}{lcc}
\hline Schirmmer I & Before & After 1 month \\
\hline Patient 1 & 2 & 3 \\
Patient 2 & 4 & 1 \\
Patient 3 & 3 & 2 \\
Patient 4 & 3 & 3 \\
Patient 5 & 2 & 2 \\
Patient 6 & 3 & 2 \\
Patient 7 & 1 & 1 \\
Patient 8 & 3 & 2 \\
Patient 9 & 1 & 1 \\
Patient 10 & 3 & 3 \\
Patient 11 & 2 & 1 \\
Patient 12 & 3 & 3 \\
\hline
\end{tabular}

p-value $=0,11$

1: schirmer variable or normal, 2 : schirmer $\leq 10 \mathrm{~mm}, 3$ : schirmer $\leq 5 \mathrm{~mm}$, 4: schirmer $\leq 2 \mathrm{~mm}$

Table 5

Break up time (BUT time) before and after PRP

\begin{tabular}{lcc}
\hline BUT time & Before & After 1 month \\
\hline Patient 1 & 2 & 2 \\
Patient 2 & 2 & 2 \\
Patient 3 & 2 & 1 \\
Patient 4 & 2 & 2 \\
Patient 5 & 2 & 1 \\
Patient 6 & 3 & 2 \\
Patient 7 & 2 & 1 \\
Patient 8 & 2 & 1 \\
Patient 9 & 2 & 1 \\
Patient 10 & 2 & 2 \\
Patient 11 & 2 & 1 \\
Patient 12 & 2 & 2 \\
\hline
\end{tabular}

p-value $=0,01$

BUT : break up time, 1: variable or normal, 2: $\leq 10$ seconds, $3: \leq 5$ seconds, 4: immediate

\section{Discussion}

Dry eye is a multifactorial disease of the tear film and ocular surface that results in symptoms of discomfort, visual disturbance and tear instability with potential damage to the ocular surface. ${ }^{14,15,16,17}$ It is accompanied by increased osmolarity of the tear film and inflammation of the ocular surface. ${ }^{17,18}$

Diabetes mellitus can cause dry eye disease, and its mechanism is probably by microvascular alterations mainly in lachrymal gland, and an ocular reflex sensory block, where reduction in sensory drive from the ocular surface is thought to favor the occurrence of dry eye in two ways: first, by decreasing reflex-induced lachrymal secretion and, second, by reducing the blink rate and, hence, increasing evaporative loss. ${ }^{18,}{ }^{19}$ Diabetes mellitus has been identified as a risk factor for dry eye in several studies, including large population studies. ${ }^{4,18,19}$

Dry eye treatment is difficult due to the multifactorial nature of this condition. A number of treatments can be used depending of the etiopathogenic factor and the severity of this disease: artificial lubricants, topical steroids, topical immunussupressants, mucolytics and secretagogues, as the most common. However, the therapeutic limitation is that an ideal substitute for the tear does not exist. ${ }^{5}$

The revolution of treatment for dry eye was the autologous serum $^{20}$ and recently, the PRP.

PRP is a major source of growth factors, with more advantages than serum. Studies shows that it has more properties for stimulating corneal reepithelization and simulates better the human tear. ${ }^{21,22,23}$ It is a preservative-free biological product, with the benefit of being obtained from the patient's own blood. ${ }^{11}$ When all sterile procedures are followed and guaranteed, the risk of infection and contamination of the bottle and ocular surface is minimal.

In the present study, we obtained preliminary results concerning the efficacy of PRP for dry eye in diabetic patients. Other studies had evaluated the use of PRP in dry eye of different etiologies. ${ }^{5,11}$

The results about the symptoms indicate that PRP is efficacious in diabetic patient with moderate to severe dry eye.

We evaluated each symptom individually. Dry eye symptoms severity generally are not associated with objective tests severity ${ }^{15}$. Treatment with PRP in the present study showed improvement in symptoms of dryness, itching, redness, and burning in all patients with statistical significance.

Considering crusting or mucus, it was present in only two patients, and both had absence of this complaint after PRP; blurred vision was present in 9 patients out of 12, and 7 had improvement of this symptom after treatment. Those two variables were not statistically significant.

None of the patients got worse, except in the blurred vision report, as one patient developed diabetic retinopathy during the follow up.

The improvement in these symptoms most likely occurred because of an indirect reduction of inflammation, by decreasing tear osmolarity and the dilution of proinflammatory factors in the ocular surface; and because of inhibitors of inflammation, such as the interleukin-1 receptor antagonist and inhibitors of metalloproteinases ${ }^{23,24}$ and other important growth factors, which are known to participate in corneal reepithelialization. ${ }^{5}$

Allió et al found in their research that $89 \%$ of the cases had a very relevant improvement in the symptoms, and no patient got worse either ${ }^{11}$. Lopez-Plandolit et al found in their study a $43.75 \%$ substantial improvement plus a $31.25 \%$ moderate improvement in SDEQ 3 (modified score questionnaire for dry eye $)^{5}$.It is difficult to compare those two results, however, because of the different methodology used by these authors to evaluate patient symptom: Allió evaluated the overall ocular discomfort, and Lopez-Plandolit et al. analyzed each symptom by the questionnaire score. ${ }^{24}$ but both studies found improvement in most of the symptoms like we did.

Considering improvement in visual acuity, we observed that $50 \%$ of our patients had an increase in BSCVA in at least one eye. Allió et al. observed that $28 \%$ of their patients had improvement in at least one eye ${ }^{11}$. We could attribute this disparity to the different inclusion/exclusion criteria, and because we evaluated just diabetic patient.

Considering the value in millimeters, we found an improvement in Schirmer test from $6.75 \mathrm{~mm} \pm 3.66$ before treatment to $8.96 \mathrm{~mm} \pm 4.56$ after, while Lopez-Pandlolit found a Schirmer test of $4.67 \pm 5.14$ before and $6.91 \pm 6.36$ after treatment ${ }^{5}$; a little disparity possibly due to the different etiology of dry eye between our studies. In cases of dry eye overall, literature shows 
that Schirmer and other objective tests do not establish a correlation with ocular damage or subjective symptoms. ${ }^{25,26}$

In BUT test, $58.33 \%(7 / 12)$ had improvement in the test value; this result was very similar to Allio et al, where $50 \%$ of the patients improved their BUT and the other $50 \%$ remained without changes. ${ }^{11}$

The overall results shows that PRP improved signs and symptoms in the majority of patients, and good tolerance is confirmed by the fact of that all the patients requested continued use of this treatment.

Limitations of this study are the small sample size that may lead to compromised statistical analysis. In addition, there may exist other etiologic factors involved in our cases: hormonal factors, use of medication that also could cause dry eye and the possibility that non diagnosed diseases could contribute for this condition in addition to diabetes mellitus.

Possible limitation of this technique is that some diabetic patients can have difficulties in venipuncture because of their vascular alterations, as we observed in our study in four patients.

It can therefore be concluded that PRP is an interesting alternative therapy in symptomatic diabetic dry eye. In clinical practice, it is important because it may prevent complications of dry eye and improve patient well being. More clinical trials are required to create specific guidelines regarding the concentrations and treatment protocols.

\section{ACKNOWLEDEGEMENTS}

We would like to thank José Tadeu de Souza (Biochemist - HEMOAL), Dr. Zenaldo Porfírio (Microbiologist - UFAL), Delane Cristina da Silva (Biomedical - HEMOAL) and Audemario Gusmão (Biologist - UFAL) for their help preparing the PRP eyedrops.

\section{RefERENCES}

1. Manaviat MR, Rashidi M, Afkhami-Ardekani M, Shoja MR. Prevalence of dry eye syndrome and diabetic retinopathy in type 2 diabetic patients. BMC Ophthalmol. 2008;8:10.

2. Ding J, Sullivan DA. Aging and dry eye disease. Exp Gerontol. 2012 ;47(7):483-90. Review.

3. Goebbels M. Tear secretion and tear film function in insulin dependent diabetics. Br J Ophthalmol. 2000; 84(1):19-21.

4. Moss SE, Klein R, Klein BEK: Incidence of dry eye in an older population. Arch Ophthalmol. 2004;122(3):369-73.

5. López-Plandolit S, Morales MC, Freire V, Grau AE, Durán JA. Efficacy of plasma rich in growth factors for the treatment of dry eye. Cornea. 2011; 30(12):1312-7.

6. Marx RE. Platelet-rich plasma (PRP): what is PRP and what is not PRP? Implant Dent 2001; 10(4): 225-8.

7. Sammartino G, Tia M, Marenzi G, di Lauro AE, D'Agostino E, Claudio PP: Use of autologous platelet-rich plasma (PRP) in periodontal defect treatment after extraction of impacted mandibular third molars. J Oral Maxillofac Surg. 2005 Jun; 63(6):766-70.

8. Alió JL, Artola A, Rodríguez-Prats JL, Pastor S, Ruiz-Colechá J. Use of autologous plateletrich plasma in the treatment of dormant corneal ulcers. Ophthalmology. 2007; 114(7):1286-1293.e1.

9. Alió JL, Pastor S, Ruiz-Colechá J, Rodríguez A, Artola A: Treatment of ocular surface syndrome (OSS) post-laser in situ keratomileusis (LASIK) with autologous platelet-rich plasma. J Refract Surg, J Refract Surg. 2007; 23(6):617-9.
10. Alió JL, Feinbaum C: Management of dry eye (ocular surface syndrome - OSS) after refractive surgery. In: Garg A, Sheppard JD, Donnenfeld ED, Meyer D, Mehta CK, editors. Clinical diagnosis and management of dry eye and ocular surface disorders (XeroDacryology). New Delhi: Jaypee Brothers; 2006. p. 198-226.

11. Rezende MS, Silva CA, Antunes VC, Ribeiro LE, Tatsui $\mathrm{N}$, Cvintal T. Uso do concentrado de plaquetas em doença da superfície ocular / Use of platelet concentrate for ocular surface disease. Rev Bras Oftalmol. 2007;66(4): 257-61.

12. Alio JL, Colecha JR, Pastor S, Rodriguez A, Artola A. Symptomatic dry eye treatment with autologous platelet-rich plasma. Ophthalmic Res. 2007; 39(3):124-9.

13. Hess K. The vulnerable blood. Coagulation and clot structure in diabetes mellitus. Hamostaseologie. 2015; 35(1):25-33

14. Listed NA. The definition and classification of dry eye disease: report of the Definition and Classification Subcommittee of the International Dry Eye Workshop (2007). Ocul Surf. 2007; 5 (2):75-92.

15. Begley CG, Chalmers RL, Abetz L, Venkataraman K, Mertzanis P, Caffery BA, et al. The relationship between habitual patientreported symptoms and clinical signs among patients with dry eye of varying severity. Invest Ophthalmol Vis Sci. 2003; 44(11):4753-61.

16. Farris RL. The dry eye: its mechanisms and therapy, with evidence that contact lens is a cause. CLAO J. 1986 OctDec;12(4):234-46.

17. Pflugfelder SC, Jones D, Ji Z, Afonso A, Monroy D . Altered cytokine balance in the tear fluid and conjunctiva of patients with Sjögren's syndrome keratoconjunctivitis sicca. Curr Eye Res. 1999; 19(3):201-11.

18. Kaiserman I, Kaiserman N, Nakar S, Vinker S. Dry eye in diabetic patients. Am J Ophthalmol. 2005; 139(3):498-503.

19. Seifart U, Strempel I: The dry eye syndrome and diabetes mellitus. Ophthalmologe. 1994, 91(2):235-9.

20. Fox RI, Chan R, Michelson JB, Belmont JB, Michelson PE. Beneficial effect of artificial tears made with autologous serum in patients with keratoconjunctivitis sicca. Arthritis Rheu. 1984;27(4):459-461

21. Harwig D, Harloff S, Liu L, Schlenke P, Wedel T, Geerling G. Epitheliotropic capacity of a growth factor preparation produced from platelet concentrates on corneal epithelial cells: a potential agent for the treatment of ocular surface defects? Transfusion. 2004; 44(12):1724-31.

22. Vajpayee RB, Mukerji N, Tandon R, Sharma N, Pandey RM, Biswas NR, et al. Evaluation of umbilical cord serum therapy for persistent corneal epithelial defects. $\mathrm{Br} \mathrm{J}$ Ophthalmol. 2003;87(11):1312-6.

23. Anitua E, And'ýa I, Ardanza B, Nurden P, Nurden AT. Autologous platelets as a source of protein for healing and tissue regeneration. Thromb Haemost. 2004;91(1): 4-15.

24. Begley CG, Caffery B, Chalmers RL, Mitchell GL; Dry Eye Investigation (DREI) Study Group. Use of the dry eye questionnaire to measure symptoms of ocular irritation in patients with aqueous tear deficient dry eye. Cornea. 2002;21(7):664-70.

25. Pflugfelder S, Tseng S, Sanabria O, Kell H, Garcia CG, Felix C, et al. Evaluation of subjective assessments and objective diagnostic tests for diagnosing tear-film disorders known to cause ocular irritation. Cornea. 1998;17(1):38-56.

26. Schein O, Tielsch J, Munõz B, Bandeen-Roche K, West S. Relationship between signs and symptoms of dry eye in the elderly. A population-based perspective. Ophthalmology. 1997;104(9):1395-401.

\section{Corresponding Author:}

Marina Viegas Moura Rezende Ribeiro.

Rua Pref Abdon Arroxelas 251. Maceio. Brazil.

Phone: 5582-33132529

E-mail: dra.marinaribeiro@gmail.com. 